\title{
EVALUATION OF THE ACCUMULATION OF ORGANOCHLORINE PESTICIDES (OCPs) IN FISH Bostrychus sinensis GROWING THE SOAI RAP ESTUARY, HO CHI MINH CITY
}

\author{
Nguyen Xuan Tong ${ }^{1,2}$, Tran Thi Thu Huong ${ }^{3, *}$, Mai Huong ${ }^{4}$, \\ Dương Thi Thuy ${ }^{5}$, Huynh Cong Luc ${ }^{2}$ \\ ${ }^{1}$ Graduate University of Science and Technology, VAST, Vietnam \\ ${ }^{2}$ Institute for Environmental Science, Engineering and Management, \\ Industrial University of Ho Chi Minh City, Ho Chi Minh city, Vietnam \\ ${ }^{3}$ Faculty of Environment, Hanoi University of Mining and Geology, Hanoi, Vietnam \\ ${ }^{4}$ University of Science and Technology of Hanoi, VAST, Vietnam \\ ${ }^{5}$ Institute of Environmental Technology, VAST, Vietnam \\ Received 6 December 2018, accepted 14 March 2019
}

\begin{abstract}
This study was conducted from May to November 2017 to evaluate the accumulation of organochlorine pesticide chemicals (OCPs) in fish, Bostrychus sinensis, growing at the Soai Rap estuary, Ho Chi Minh City, Vietnam. The pesticide chemicals in the tissues of fish and the sediments of the estuary were analyzed using a gas chromatography method and Varian GC-450 (ECD) instrument. The results showed that in all tissue samples of fish, the content of DDTs was the highest $(9.524 \mathrm{ng} / \mathrm{g})$, followed by aldrin $(1.209 \mathrm{ng} / \mathrm{g}) ; \mathrm{HCHs}(1.972 \mathrm{ng} / \mathrm{g})$; dieldrin $(1.743$ $\mathrm{ng} / \mathrm{g})$ and endosunfans $(1.053 \mathrm{ng} / \mathrm{g})$, and the lowest values were Heptachlor $(0.807 \mathrm{ng} / \mathrm{g})$ and Eldrin $(0.715 \mathrm{ng} / \mathrm{g})$. The content of OCPs in all sediment samples from the study area was found to be lower than Vietnamese standard 43: 2012 /MONRE and some other standards in the world. The bioaccumulation factor of OCPs in the tissue of fish was very low level (BAF $<100$ ), for DDTs at low levels $(100<\mathrm{BAF}<500)$. The Biota-Sediment Accumulation Factor (BSAF) of the seven substances in the sediment was Dieldrin > DDTs > Aldrin > HCHs > Endosunfans > Heptachlor > Endrin.
\end{abstract}

Keywords: Bostrychus sinensis, bioaccumulation factors, biota-sediment accumulation factor, estuary, fish, organochlorine pesticide (OCPs).

Citation: Nguyen Xuan Tong, Tran Thi Thu Huong, Mai Huong, Dương Thi Thuy, Huynh Cong Luc, 2019. Evaluation of the accumulation of organochlorine pesticides (OCPs) in fish Bostrychus sinensis growing the Soai Rap estuary, Ho Chi Minh city, 41(1): 129-140. https://doi.org/10.15625/0866-7160/v41n1.13358.

*Corresponding author email: huonghumg@gmail.com

@2019 Vietnam Academy of Science and Technology (VAST) 


\title{
ĐÁNH GIÁ SỰ TÍCH LŨY HÓA CHẤT BẢO VỆ THỰC VẬT OCPs Ở CÁ BớP Bostrychus sinensis SINH TRƯởNG TẠI CỬA SÔNG SOÀI RẠP, Tp. HỒ CHÍ MINH
}

\author{
Nguyễn Xuân Tòng1,2, Trần Thị Thu Hương ${ }^{3, *}$, Mai Hương ${ }^{4}$, \\ Dương Thị Thủy ${ }^{5}$, Huỳnh Công Lực ${ }^{2}$
}

${ }^{1}$ Học Viện Khoa học và Công nghệ, Viện Hàn lâm Khoa học và Công nghệ Việt Nam, Việt Nam

${ }^{2}$ Viện Khoa học Công nghệ và Quản lý Môi trường, Trường Đại học Công nghiệp thành phố Hồ

Chí Minh, thành phố Hồ Chí Minh, Việt Nam

${ }^{3}$ Khoa Môi trường, Trường Đại học Mỏ Địa chất Hà Nội, Hà Nội, Việt Nam

${ }^{4}$ Trường Đại học Khoa học và Công nghệ Hà Nội, Viện Hàn lâm Khoa học và

Công nghệ Việt Nam, Việt Nam

${ }^{5}$ Viện Công nghệ Môi trường, Viện Hàn lâm Khoa học và Công nghệ Việt Nam, Việt Nam

Ngày nhận bài 6-12-2018, ngày chấp nhận 14-3-2019

\section{TÓM TẮT}

Nghiên cứu này được tiến hành từ tháng 5 đến tháng 11 năm 2017 nhằm đánh giá sự tích lũy hóa chất bảo vệ thực vật họ clo (OCPs) ở cá bớp, Bostrychus sinensis, sinh trưởng tại khu vực cửa sông Soài Rạp, tp Hồ Chí Minh. Hàm lượng hóa chất bảo vệ thực vật họ clo (OCPs) trong mẫu mô cá và mẫu trầm tích đáy được xác định bằng phương pháp sắc ký khí trên thiết bị Varian GC450 (ECD). Kết quả cho thấy, trong tất cả mẫu mô cá hàm lượng DDTs là lớn nhất $(9,524 \mathrm{ng} / \mathrm{g})$, tiếp theo là aldrin $(1,209 \mathrm{ng} / \mathrm{g})$; HCHs $(1,972 \mathrm{ng} / \mathrm{g})$; dieldrin $(1,743 \mathrm{ng} / \mathrm{g})$ và endosunfans $(1,053$ $\mathrm{ng} / \mathrm{g})$, nhóm thấp nhất là heptachlor $(0,807 \mathrm{ng} / \mathrm{g})$ và Eldrin $(0,715 \mathrm{ng} / \mathrm{g})$. Đã phát hiện hàm lượng các hợp chất $\mathrm{OCPs}$ trong tất cả các mẫu trầm tích tại khu vực nghiên cứu và đều thấp hơn giới hạn quy định theo QCVN 43:2012/BTNMT và một số tiêu chuẩn khác trên thế giới. Hệ số tích tụ sinh học của các chất OCPs trong mô thịt cá bớp ở mức rất thấp (BAF< 100) riêng DDTs ở mức tích tụ thấp $(100<\mathrm{BAF}<500)$. Hệ số tích lũy sinh học (BSAF) của 7 loại hoạt chất trong trầm tích theo thứ tự Dieldrin $>$ DDTs $>$ Aldrin $>\mathrm{HCHs}>$ Endosunfans $>$ Heptachlor $>$ Endrin.

Từ khóa: Bostrychus sinensis, cửa sông, hệ số tích lũy sinh học, hệ số tích lũy trầm tích, OCPs.

*Địa chỉ liên hệ email: huonghumg@ gmail.com

\section{MỞ ĐÀ̀U}

Thủy sản Việt Nam trong những năm gần đây không những đáp ứng được thị trường trong nước mà còn trở thành mặt hàng xuất khẩu chủ lực. Tính đến cuối năm 2017, Việt Nam đã xuất khẩu được 7.225 nghìn tấn thủy sản, tăng 5,5\% so với năm 2016, với số lượng và chủng loại rất đa dạng, trong đó chủ yếu là cá, đạt 5.192,4 nghìn tấn; tôm đạt 887,5 nghìn tấn (VASEP, 2016). Theo thống kê của Tổ chức Nông Lương Thế giới (FAO), Việt Nam đã trở thành nước sản xuất thủy sản lớn thứ ba của thế giới, chỉ sau Trung Quốc và Ấn Độ (FAO, 2009). Trước đây, phần lớn sản phẩm được xuất khẩu, còn hiện nay, sản phẩm thủy sản đã và đang có một vị trí quan trọng trong bữa ăn hàng ngày của người Việt (Pham et al., 2015). Tuy nhiên, do chưa có quy hoạch tổng thể và định hướng bài bản, nhiều cơ sở và trang 
trại nuôi trồng chưa có hệ thống xử lý nước nuôi và nước thải làm ô nhiễm nguồn nước.

Cá bớp, Bostrychus sinensis, còn có tên là cá bống bớp hay cá bống bốn mắt, là một loài cá nước lợ thuộc họ Cá bống đen. Cá bớp không những được thị trường trong nước ưa chuộng mà còn được xuất khẩu sang một số nước. Ở Việt Nam, cá bớp thường sống trong các hang đất phân bố dọc theo bờ biển từ Bắc đến Nam ở rừng ngập mặn, cửa sông và các vùng triều. Công bố của IUCN không đánh giá mức độ nguy cẩp của loài, nhưng ở Việt Nam, đây là loài cực kỳ nguy cấp, cũng do cá bớp là nguồn thực phẩm có giá trị dinh dưỡng cao, thịt thơm ngon, đồng thời là mặt hàng xuất khẩu có giá trị cao nên bị đánh bắt nhiều, điều này dẫn đến quần thể của chúng trong tự nhiên bị sụt giảm mạnh, đối diện với nguy cơ tuyệt chủng (IUCN, 2007). Đứng trước thực trạng này, những năm gần đây, việc nhân rộng mô hình nuôi nhân tạo cá bớp đã được mở rộng. Tuy nhiên, việc nhân rộng mô hình nuôi nhân tạo cũng làm gia tăng ô nhiễm môi trường, ảnh hưởng lớn đến quá trình sinh trưởng, phát triển cũng như chất lượng sản phẩm thu hoạch của loài thủy sản này.

Hóa chất bảo vệ thực vật họ clo (OCPs) thuộc nhóm ô nhiễm hữu cơ bền (POPs), có khả năng gây rối loạn nội tiết, ảnh hưởng đến thần kinh, gây tác động xấu cho nội tạng và gây ung thư cho con người (Donaldson et al., 2002). Sự có mặt của nhóm hóa chất này trong các con sông thông qua việc thoát nước và sử dụng không hợp lý trong nông nghiệp có thể gây ra những ảnh hưởng sinh thái và nguy hiểm cho sự sinh trưởng, sinh sản hoặc sống còn của các loài sinh vật trong hệ sinh thái sông và cửa sông, kể cả loài tự nhiên hay nuôi trồng (Banerjee et al., 1996). Theo Tran et al. (2013), dẫn xuất dipterex đã gây nên hiện tượng phù và xuất huyết, đồng thời làm tăng hoạt tính của enzyme AChE ơ cơ của cá rô phi (Oreochromis niloticus) sau 72 giờ tiếp xúc với dipterex ở nồng độ $0,25 \mathrm{ppm}$. Nguyen et al (2011) đã chỉ ra hóa chất bảo vệ thực vật chứa hoạt chất diazinon rất độc đối với cá lóc đồng (Channa striata) ở giai đoạn cá giống và làm tử vong cá con do diazinon đã ức chế enzyeme cholinesterase, làm giảm tăng trưởng của cá. Kết quả nghiên cứu của Tran et al. (2012) và Nguyen et al. (2012) cho thấy hóa chất bảo vệ thực vật quinalphos làm giảm tăng trưởng ở cá chép Cyprinus carpio và cá mè Barbodes gonionotus) và khả năng ảnh hưởng tăng khi nồng độ thuốc tăng.

Hiện nay, ở Việt Nam, nghiên cứu về ảnh hưởng và tích lũy $\mathrm{OCPs}$ trong mô thịt của các loài thuỷ sinh vật vẫn chưa được nghiên cứu và công bố nhiều. Tại khu vực nghiên cứu, cửa sông Soài Rạp, tp. Hồ Chí Minh, nơi chịu tác động của chế độ bán nhật triều 2 lần trong ngày, thời gian triều lên không đủ để pha loãng các chất ô nhiễm cũng như không kịp đẩy chất ô nhiễm ra ngoài biển khi triều xuống, vì vậy, ô nhiễm tại đây luôn cao hơn các vị trí khác (DONRE, 2017). Đây cũng là nơi chất lượng nước sông đang bị đe dọa nghiêm trọng do tiếp nhận nhiều nguồn ô nhiễm từ nước thải, chất thải rắn và nước từ sản xuất nông nghiệp có chứa phân bón, thuốc trừ sâu từ các tỉnh Long $\mathrm{An}$, Tiền Giang và thành phố Hồ Chí Minh (DONRE, 2017; Nguyen et al., 2007). Để có những biện pháp phù hợp trong việc phòng ngừa tồn lưu các chất $\hat{o}$ nhiễm gây độc và đảm bảo an toàn thực phẩm, tránh ảnh hưởng đến hoạt động nuôi trồng thủy sản, cần đánh giá được khả năng tích lũy OCPs trong cá bớp $B$. sinensis.

\section{VÂT LIỆU VÀ PHƯƠNG PHÁP NGHIÊN CúU}

\section{Thu mẫu sinh vật}

Cá bớp $B$. sinensis được thu mẫu ngẫu nhiên 8 lần theo 8 đợt đánh bắt khác nhau của ngư dân địa phương, trong thời gian từ tháng 5 đến tháng 11 năm 2017 (Ký hiệu mẫu từ SR1-SR8). Mẫu thu ở kích thước thương phẩm, lấy mẫu và bảo quản mẫu theo TCVN 5992:1995 (ISO 7828:1995), TCVN 5276:1990. Khu vực lấy mẫu là vùng cửa sông Soài Rạp thuộc hệ thống sông Sài GònĐồng Nai, đoạn hạ lưu của sông Nhà Bè (tính từ Nam Hiệp Phước-Nhà Bè ra đến Vịnh Đồng Tranh, hình 1). 


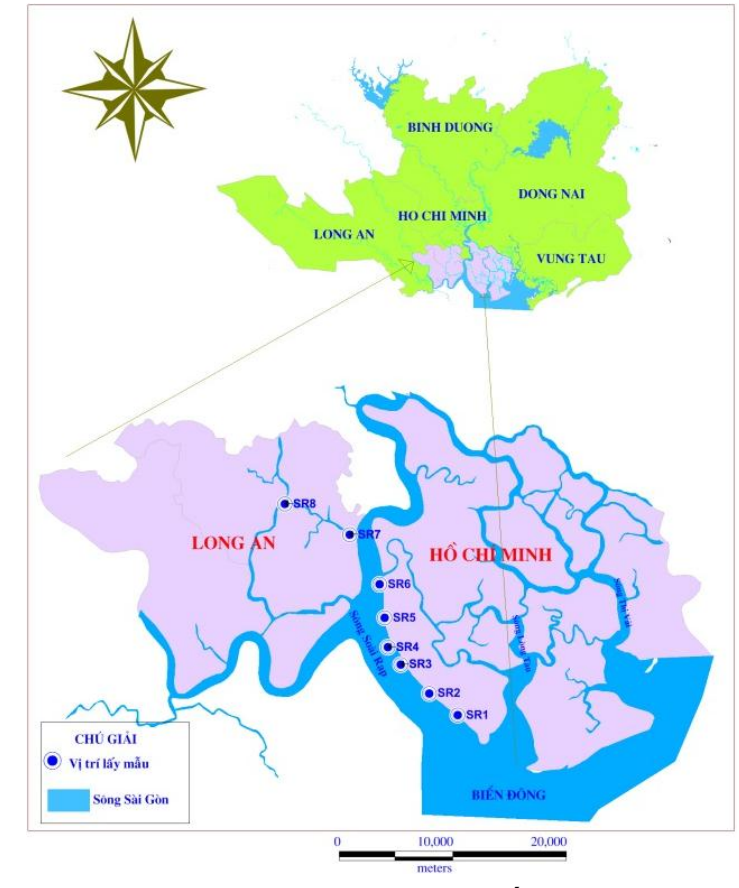

Hình 1. Khu vực và vị trí lấy mẫu cá và trầm tích

\section{Thu mẫu trầm tích}

Mẫu trầm tích được thu đồng thời tại các vị trí thu mẫu cá bằng gàu Ekman có diện tích miệng gàu là $0,036 \mathrm{~m}^{2}$, trầm tích được lấy ở lớp bề mặt khoảng từ $0-10 \mathrm{~cm}$, trộn đều cho vào túi polyetilen và bao gói bằng giấy nhôm, bảo quản trong hộp, làm lạnh bằng đá gel rồi chuyền về phòng thí nghiệm. Sau khi hong khô, mẫu được nghiền nhỏ, rây qua rây có kích thước $0,63 \mu \mathrm{m}$ và phân tích hàm lượng OCPs. Các mẫu được bảo quản ở nhiệt độ $4^{\circ} \mathrm{C}$, trước khi phân tích mẫu được rã đông về nhiệt độ phòng và xác định hệ số khô kiệt theo TCVN 6648:2000.

\section{Phương pháp xác định hàm lượng OCPs}

Mẫu mô cá được nghiền đều bằng máy chuyên dụng và làm khô bằng $\mathrm{Na}_{2} \mathrm{SO}_{4}$ khan. Chiết siêu âm và ly tâm $20 \mathrm{~g}$ mẫu sinh học khô ba lần bằng dung môi $\mathrm{n}$-hexan/acetone (1:1). Dịch chiết được cô quay chân không về khoảng $5 \mathrm{ml}$ và cho qua cột sắc ký thẩm thấu gel để loại bỏ các chất béo, amin... có trong mẫu chiết. Sau đó, tiếp tục làm sạch bằng cột silicagel $2 \mathrm{~g}$. Rửa giải $\mathrm{OCPs}$ bằng $\mathrm{n}$-hexan
(3×15 ml), dịch rửa giải được cô về dưới $1 \mathrm{ml}$, thêm chất nội chuẩn và định mức đến $1 \mathrm{ml}$ bằng n-hexane (Duong et al., 2013; Tran et al., 2007; Tsygankov et al., 2015). Mẫu sinh học trước khi chiết đã được đồng hóa bằng $\mathrm{Na}_{2} \mathrm{SO}_{4}$ khan. Tổng lượng OCPs trong mẫu được xác định bằng phương pháp sắc ký khí trên thiết bị Varian GC-450, Detector cộng bắt bẫy điện tử (ECD) tại Phòng Phòng Độc học sinh thái, Đại học Lige (Bỉ) và Phòng Phân tích môi trường, Đại học Công nghiệp thành phố Hồ Chí Minh.

\section{Cách tính hệ số BAF}

Hệ số tích tụ sinh học là tỷ lệ nồng độ hóa học trong mô của của sinh vật sống với nồng độ chất đó trong môi trường nước (Arnot et al., 2006):

$$
B A F=C_{B} / C_{W}
$$

Trong đó: BAF: Hệ số tích tụ sinh học được tính toán bằng số liệu thực nghiệm, giá trị của hệ số tính theo đơn vị mô thịt ướt của sinh vật; $C_{B}$ là nồng độ của chất ô nhiễm trong mô sinh vật $\left(\mathrm{mg} / \mathrm{kg}\right.$ mô thịt khô); $C_{W}$ là nồng độ của chất ô nhiễm trong nước $(\mathrm{mg} / \mathrm{l})$.

\section{Tính hệ số BSAF}

Hệ số tích tụ trong trầm tích tại môi trường nơi cá bớp $B$. sinensis sinh sống được xác định bằng phương trình sau (David et al., 2010):

$$
B A S F=\frac{C_{o} / f_{l}}{C_{s} / f_{\text {Soc }}}
$$

Trong đó: BSAF: Hệ số tích tụ sinh học trong trầm tích được tính toán bằng số liệu thực nghiệm; $C_{o}$ : Nồng độ hóa chất trong sinh vật (ng/g khối lượng ướt); $f_{l}$ : Phần lipit của sinh vật (ng lipit/g khối lượng ướt); $C_{s}$ : nồng độ hóa chất trong trầm tích bề mặt (ng/g khối lượng khô); $f_{s o c}$ : Cacbon hữu cơ trong trầm tích (ng cacbon hữu cơ/g khối lượng khô).

Hàm lượng cacbon hữu cơ trong trầm tích được phân tích và tính toán theo phương pháp phân tích đất và nước của Walkley và Black (Singh et al., 2014). 


\section{Xử lý số liệu}

Các số liệu của bài báo được thống kê, tính toán và vẽ bằng phần mềm GrapPad Primse 6 và Sigmaplot 12.5 với ý nghĩa thống kê $\rho<0,05$.

\section{KẾT QUẢ VÀ THẢO LUẬN}

\section{Hàm lượng các chất OCPs trong mô thịt cá bớp}

Hàm lượng các hoạt chất OCPs (bao gồm các chất HCHs, DDTs, heptachlor, aldrin, dieldrin, endrin, endosulfans và tổng $\mathrm{OCPs}$ ) tích lũy trong mô thịt cá bớp $B$. sinensis tại khu vực nghiên cứu được tổng hợp trong bảng 1 và hình 2 . Kết quả cho thấy sự chênh lệch hàm lượng OCPs tổng giữa các mẫu là khá lớn từ 7,685 ng/g đến 40,297 ng/g, song giá trị trung bình OCPs tổng và từng hoạt chất trong các mẫu tồn lưu khá thấp, phân bố chủ yếu trong khoảng giá trị 0,773-19,519 ng/g (hình 2). Bảng 1 cho thấy, hàm lượng DDTs cao đột biến hơn các dẫn xuất khác với giá trị trong khoảng 2,6182-19,911 ng/g, hàm lượng $\mathrm{HCHs}$ ghi nhận giá trị từ $0,804-$ $6,555 \mathrm{ng} / \mathrm{g}$, các dẫn xuất còn lại gồm heptachlor, endosunfans và các hợp chất drins có giá trị khá thấp chủ yếu trong khoảng từ $0-5,420 \mathrm{ng} / \mathrm{g}$ khối lượng ướt $(\alpha=$ 0,05 ). Hàm lượng aldrin và dieldrin trong các mẫu không chênh lệch quá cao, chủ yểu là dieldrin cao hơn aldrin, do aldrin dễ chuyển hóa thành dieldrin trong môi trường. Hàm lượng dieldrin trung bình là $1,743 \mathrm{ng} / \mathrm{g}$ và thấp hơn nhiều lần so với giới hạn cho phép của Cục Quản lý Dược phâm và Thực phẩm Hoa Kỳ $(0,3 \mathrm{ppm}$ và $5 \mathrm{ppm}$ tương ứng đối với các hợp chât drins, heptachlor, $\mathrm{HCHs}$ và với DDTs) (USEPA, 1997a) và các tiêu chuẩn của Ôxtrâylia, châu Âu hay Tổ chức Nông lương Liên Hợp quốc (FAO) (Sankar et al., 2006; APVMA, 2012; Stefanelli et al., 1997). Phân tích ANOVA ghi nhận giá trị hàm lượng các chất OCPs khác biệt có ý nghĩa về mặt thống kê $(\rho=0,0183)$.
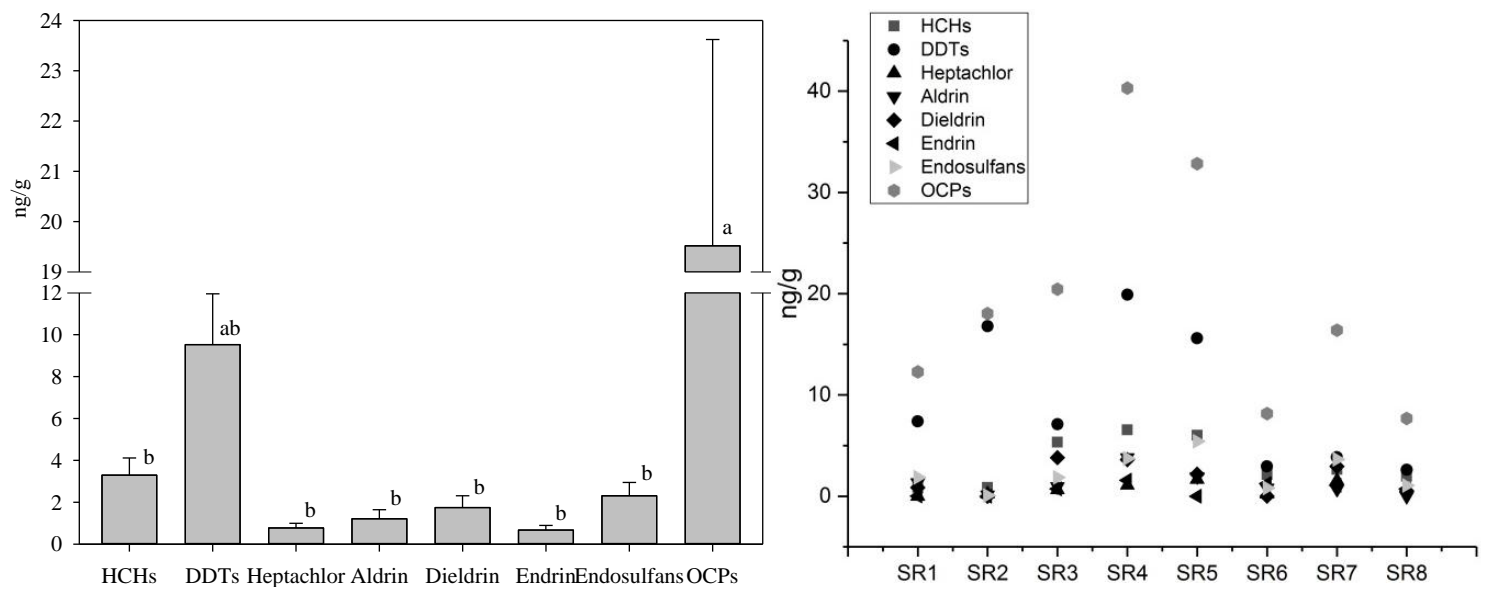

Hình 2. Tỷ lệ hàm lượng và phân bố các chất OCPs trong các mẫu mô thịt cá bớp ở cửa sông Soài Rạp, thành phố Hồ Chí Minh

Kết quả phân tích ghi nhận ở cửa sông Soải Rạp, thành phố Hồ Chí Minh thấp hơn so với một số giá trị đã công bố trước đây (Wang et al., 2012; Daniela et al., 2008; Yohannes, 2014; Dai et al., 2011). Theo Wang et al (2012), nồng độ trung bình tổng DDT trong mô của cá vàng Carassius auratus và vẹm lần lượt là 369,118 và $79,1 \mathrm{ng} / \mathrm{g}$, cao hơn nhiều so với các khu vực khác của Trung Quốc.
Điều này có thể do DDT đã được sử dụng nhiều trong khu vực nghiên cứu và do ái lực cao của thuốc trừ sâu organochlorine trong các mẫu lipid, mô cá, mô trai và khả năng tồn lưu bền, khó phân hủy của chúng trong môi trường. Daniela et al. (2008) lại cho rằng các đồng phân $\alpha$ và $\gamma$ của $\mathrm{HCH}$ và heptachlor được phát hiện thường xuyên nhất trong các mẫu trầm tích $(0,017-0,044 \mu \mathrm{g} / \mathrm{g})$ và mẫu cá 
$(0,051-0,203 \mu \mathrm{g} / \mathrm{g})$. Hàm lượng của các hợp chất tìm thấy không cao song sự có mặt của chúng trong môi trường cho thấy chúng vẫn đang được sử dụng dù đã được pháp luật nghiêm cấm sử dụng cách đây nhiều năm. Nghiên cứu của Yohannes et al. (2014) lại ghi nhận DDTs là chất gây ô nhiễm chủ yếu $(0,9 \mathrm{ng} / \mathrm{g}$ đến $61,9 \mathrm{ng} / \mathrm{g})$, tiếp theo là $\mathrm{HCHs}$, chlordanes và heptachlors trên tổng các giá trị OCPs khác nhau (từ $1,41 \mathrm{ng} / \mathrm{g}$ đến $63,8 \mathrm{ng} / \mathrm{g}$ khối lượng ướt). Uuu thế của DDT có thể do hiện tại chúng được sử dụng như một véc tơ kiểm soát ô nhiễm OCPs kêt hợp với tồn lưu DDTs trong khu vực nghiên cứu từ trước đó.
Ngược lại, hàm lượng tương đối thấp của $\mathrm{PCB}, \mathrm{HCH}$ và $\mathrm{DDT}$ (nồng độ trung bình từ $0,28 \mathrm{ng} / \mathrm{g}$ đến $3,28 \mathrm{ng} / \mathrm{g}$ ) đã được Dai et al. (2011) ghi nhận trong mô cá lóc, cá trắm cỏ ở hồ Baiyangdian, Hà Bắc, Trung Quốc. Hàm lượng cao nhất là ở cá lóc $(7,39 \mathrm{ng} / \mathrm{g})$ và thấp nhất là cá trắm cỏ $(2,04 \mathrm{ng} / \mathrm{g}$, khối lượng ướt). Mặc dù nồng độ các chất OCPs không vượt quá giới hạn cho phép của Trung Quốc và tiêu chuẩn USFDA, song sự hiển diện của chúng trong môi trường vẫn tiềm ẩn những rủi ro sinh thái và nguy cơ đối với sức khỏe con người khi ăn phải nguồn thực phẩm phơi nhiễm các chất này trong một thời gian dài.

Bảng 1. Hàm lượng các hóa chất bảo vệ thực vật OCPs trong mô thịt cá bớp (khối lượng ướt, $\mathrm{ng} / \mathrm{g}$ )

\begin{tabular}{|l|c|c|c|c|c|c|c|c|}
\hline \multicolumn{1}{|c|}{ Mẫu } & HCHs & DDTs & Heptachlor & Aldrin & Dieldrin & Endrin & Endosulfans & $\Sigma$ OCPs \\
\hline SR1 & 0,804 & 7,394 & 0 & 1,344 & 0,853 & 0,022 & 1,870 & 12,286 \\
\hline SR2 & 0,853 & 16,780 & 0,201 & 0,133 & 0 & 0 & 0,068 & 18,035 \\
\hline SR3 & 5,344 & 7,108 & 0,639 & 0,942 & 3,822 & 0,734 & 1,857 & 20,445 \\
\hline SR4 & 6,555 & 19,911 & 1,098 & 3,815 & 3,609 & 1,580 & 3,729 & 40,297 \\
\hline SR5 & 6,019 & 15,594 & 1,666 & 1,951 & 2,193 & 0 & 5,420 & 32,844 \\
\hline SR6 & 2,136 & 2,941 & 0,216 & 0,801 & 0 & 1,251 & 0,817 & 8,162 \\
\hline SR7 & 2,651 & 3,843 & 1,554 & 0,688 & 2,948 & 1,070 & 3,644 & 16,398 \\
\hline SR8 & 1,972 & 2,618 & 0,807 & 0 & 0,520 & 0,715 & 1,053 & 7,685 \\
\hline TB & 3,292 & 9,524 & 0,773 & 1,209 & 1,743 & 0,671 & 2,307 & 19,519 \\
\hline + SD & 0,823 & 2,431 & 0,222 & 0,433 & 0,564 & 0,218 & 0,637 & 4,104 \\
\hline $\begin{array}{l}\text { (1) USFDA } \\
\text { 2001 }\end{array}$ & 300 & 5000 & 300 & 300 & 300 & 300 & & \\
\hline $\begin{array}{l}\text { (2) EU MRL } \\
\text { (3) Australian } \\
\text { ERL }\end{array}$ & 1000 & 1000 & & & 200 & 50 & 100 & \\
\hline (4) FAO 1983 & 300 & 3000 & & 100 & 100 & & & \\
\hline
\end{tabular}

Ghi chú: SD - Standard deviation: độ lệch chuẩ; Đơn vị tính: ng/g khối lượng ướt; SR1-SR8: các mẫu thu tại khu vực nghiên cứu; Giới hạn cho phép (GHCP) theo một số quy định quốc tế: (1), (4): Sankar et al. (2006); (2): Stefanelli et al. (2004); (3): APVMA (2012).

Hàm lượng các chất OCPs trong trầm tích tại khu vực nghiên cứu

Kết quả phân tích mẫu trầm tích được lấy ở khu vực nghiên cứu đã phát hiện cả bảy nhóm chất OCPs (bảng 2). Trong đó, hàm lượng dieldrin cao nhât: $2,410 \mathrm{ng} / \mathrm{g}$; $\mathrm{t}$ DDTs: $1,392 \mathrm{ng} / \mathrm{g}$; aldrin: $0,648 \mathrm{ng} / \mathrm{g}$; HCHs: $0,622 \mathrm{ng} / \mathrm{g}$; endosunfans:0,561 ng/g; endrin: $0,489 \mathrm{ng} / \mathrm{g}$ và thấp nhất là heptachlor: $0,334 \mathrm{ng} / \mathrm{g}$. Hàm lượng trung bình các chất OCPs đều có sự biên động tương tự nhau, có xu hướng tỷ lệ thuận với hàm lượng tích lũy trong mô cá (hình 3 ) và đều thấp hơn giới hạn cho phép theo QCVN 43:2012/BTNMT và tiêu chuẩn USEPA (USEPA, 1997a; MacDonald, 1994). 
Bảng 2. Hàm lượng các chất $\mathrm{OCPs}$ trong trầm tích tại khu vực nghiên cứu (khối lượng ướt, ng/g)

\begin{tabular}{|l|c|c|c|c|c|c|c|c|}
\hline $\begin{array}{l}\text { Hợp chất } \\
\text { Giá trị }\end{array}$ & HCHs & DDTs & Heptachlor & Aldrin & Dieldrin & Endrin & Endosulfans & $\Sigma$ OCPs \\
\hline Mean & 0,622 & 1,392 & 0,334 & 0,648 & 2,410 & 0,489 & 0,561 & 0,826 \\
\hline SE & 0,143 & 0,310 & 0,125 & 0,206 & 1,010 & 0,163 & 0,164 & 0,154 \\
\hline Max & 1,292 & 2,834 & 1,118 & 1,895 & 8,672 & 1,098 & 1,289 & 1,710 \\
\hline Min & 0,174 & 0,469 & 0,000 & 0,000 & 0,000 & 0,000 & 0,022 & 0,330 \\
\hline $\begin{array}{l}\text { (1) QCVN } \\
\text { 43:2011 }\end{array}$ & & 4,8 & 2,7 & & 4,3 & 62,4 & & \\
\hline (2) PEL & 0,99 & 51,7 & 2,74 & & 6,67 & 62,4 & & \\
\hline (3) USEPA & & & & & & & 540 & \\
\hline
\end{tabular}

Ghi chú: Hàm lượng các chất và $\Sigma$ OCPs tính theo ng/g, khối lượng ướt; (1): Giới hạn cho phép (GHCP) theo qui định QCVN 43:2012/BTNMT: Quy chuẩn kỹ thuật quốc gia về chất lượng trầm tích; (2), (3): MacDonald (1994) và USEPA (1997a).

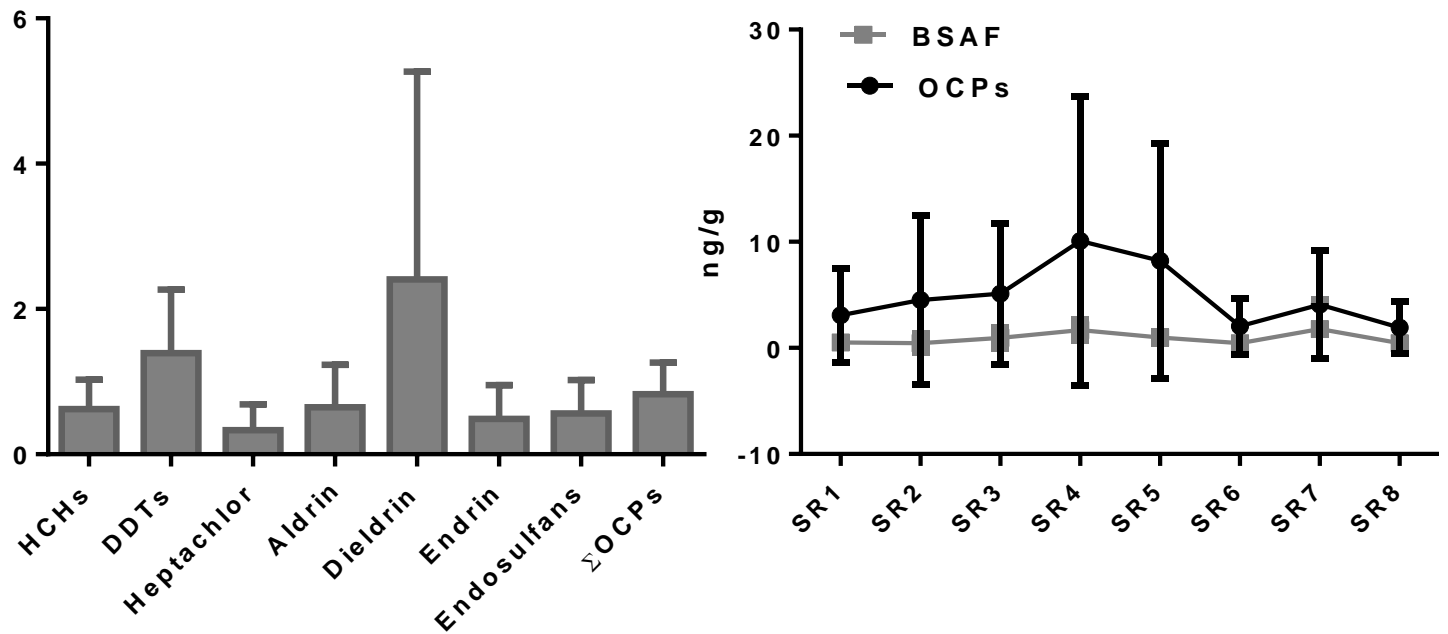

Hình 3. Biểu đồ phân bố hàm lượng các chất $\mathrm{OCP}$ s trong trầm tích và tỷ lệ tương quan hàm lượng $\Sigma \mathrm{OCP}$ s trong trầm tích và trong mô thịt cá bớp Bostrychus sinensis

Ghi chú: SR1-SR8: là các mẫu thu tại khu vực nghiên cứu

Trầm tích có khả năng hút và lưu trữ cao đối với các hợp chất hữu cơ kỵ nước. Chúng có thể hoạt động như một nguồn gây ô nhiễm thứ cấp cho cột nước và các loại sản phẩm thủy sản liên quan đến trầm tích $(\mathrm{Wu}$ et al., 2013). Kết quả nghiên cứu của Aamir et al. (2016) ghi nhận giá trị BSAF tương tự đối với tổng $\mathrm{HCH}$ và tổng $\mathrm{DDT}$ trong bốn loài cá Orienus plagiostomus, Tor putitora, Glyptothorax punjabensis và Cyprinus carpio dao động từ $0,6 \mathrm{ng} / \mathrm{g}$ đến $1,5 \mathrm{ng} / \mathrm{g}$ và từ 0,2 $\mathrm{ng} / \mathrm{g}$ đến $1,6 \mathrm{ng} / \mathrm{g}$ với mức độ tin cậy là $95 \%$. Hàm lượng cacbon hữu cơ và lipid trong trầm tích đã có ảnh hưởng lớn đến giá trị BSAF của bốn loài cá được nghiên cứu. Theo ghi nhận của Chen et al. (2010), hàm lượng tổng OCPs trong nước và trầm tích dao động tương ứng từ không phát hiện đến $195 \mathrm{ng} / \mathrm{g}$ (trong nước) và từ $1,36 \mathrm{ng} / \mathrm{g}$ đến $24,60 \mathrm{ng} / \mathrm{g}$ (trong trầm tích). Một số công bố khác đã chỉ ra các dẫn xuất của DDT có độ hấp phụ tương đối cao, độ hòa tan trong nước thấp, có độc tính thủy sinh cao hơn, tích lũy sinh học cao hơn, tồn tại lâu hơn so với $\mathrm{HCH}$ và dễ phân vùng giữa sinh khối với trầm tích (Kaushik et al., 2012; Wang et al., 2010). Đặc tính kỵ nước là một 
trong những yếu tố quan trọng ảnh hưởng đến khả năng tích lũy sinh học trong trầm tích của các hợp chất được nghiên cứu và việc ghi nhận sự có mặt của các hợp chất OCPs trong trầm tích tại khu vực nghiên cứu thường xuyên có thể gây ra tác dụng phụ đối với một số loài sinh vật sinh trưởng và phát triển tại đây (Cheng et al., 2013). Đánh giá sự tích lũy các chất OCPs trong
cá bớp Bostrychus sinensis

Hệ số tích tụ sinh học (BAF) được tính toán dựa vào hàm lượng các hợp chất $\mathrm{OCPs}$ trong môi trường nước (thức ăn) và trong cơ thể cá bớp nuôi ở cùng một thời điểm thu mẫu. Kết quả nghiên cứu cho thấy hệ số $\mathrm{BAF}$ của các chất OCPs có giá trị khác nhau trong các mẫu mô thịt cá bớp $B$. sinensis (bảng 3 ). Giá trị thấp nhất là heptachlor $(33,649 \mathrm{ng} / \mathrm{g})$ và lớn nhất là DDTs $(386,383 \mathrm{ng} / \mathrm{g}$, khồi lượng ướt). Tất cả các giá trị tính toán được đều ở mức rất thấp $(\mathrm{BAF}<250)$ trừ hợp chất DDTs ở mức thấp $(100<\mathrm{BAF}<500)$ (MacDonald, 1994) và có sự khác biệt so với các OCPs còn lại, kết quả phân tích hậu ANOVA ghi nhận $\rho<0,0001$.

Bảng 3. Hệ số tích tụ sinh học (BAF) của các hợp chất OCPs trong mô thịt cá bớp Bostrychus sinensis (ng/g, khối lượng ướt)

\begin{tabular}{|l|c|c|c|c|c|c|c|c|}
\hline $\begin{array}{c}\text { Giá } \\
\text { trị }\end{array}$ & HCHs & DDTs & Heptachlor & Aldrin & Dieldrin & Endrin & Endosulfans & $\Sigma$ OCPs \\
\hline Mean & 99,046 & 386,383 & 33,649 & 74,496 & 61,645 & 68,119 & 78,133 & 109,882 \\
\hline SE & 27,985 & 86,336 & 11,960 & 25,040 & 23,207 & 24,151 & 20,834 & 19,881 \\
\hline Max & 211,466 & 765,808 & 103,587 & 224,418 & 196,533 & 197,451 & 169,379 & 210,980 \\
\hline Min & 25,928 & 145,456 & 0,000 & 0,000 & 0,000 & 0,000 & 2,125 & 54,894 \\
\hline
\end{tabular}

Đánh giá khả năng tích tụ các OCPs trong một số loài cá khác cũng cho kết quả tương tự (Barnhoorn et al., 2015; Buah-Kwofie et al., 2018; Binelli et al., 2003; Yohannes et al., 2013; Wepener et al., 2012). Ở Ethiopia nơi DDT vẫn được sử dụng để kiểm soát sốt rét, nồng độ $\Sigma$ DDT phát hiện được ở cá trê $C$. gariepinus và cá rô phi $O$. mossambicus cao hơn mức phát hiện tại Simangaliso (Nam Phi) và Bosomtwi (Ghana), mặc dù hàm lượng $\Sigma \mathrm{HCH}$, heptachlor, dieldrin và $\alpha$-endosulfan ghi nhận trong cá từ iSimangaliso cao hơn vài lần so với ghi nhận ở hồ Ziway, Ethiopia (4 $520 \mathrm{ng} / \mathrm{g} \Sigma \mathrm{HCH})$ và hồ Bosomtwi, Ghana (0,8-2,3 ng/g $\alpha$-endosulfan) (Barnhoorn et al, 2015; Buah-Kwofie et al., 2018). Các OCPs khác, bao gồm $\Sigma \mathrm{HCH}$, heptachlor, $\alpha$ endosulfan và dieldrin, nói chung cũng được phát hiện ở nồng độ thấp hơn khi so sánh với mức tìm thấy ở $C$. gariepinus và $O$. mossambicus tại Ethiopia. Theo các tác giả này, nguyên nhân là do các hợp chất DDTs như $\mathrm{p}, \mathrm{p}^{\prime}$-DDE, $\mathrm{p}, \mathrm{p}^{\prime}$-DDD có khả năng chuyển hóa ổn định hơn các OCPs khác (Yohannes et al., 2013; Wepener et al., 2012) hoặc chu kỳ bán rã của OCPs DDTs là khác nhau ở các loài cá khác nhau, chu kỳ bán rã của $\mathrm{p}, \mathrm{p}^{\prime}$-DDT trong cá là khoảng tám tháng, trong khi chu kỳ bán rã của $p, p^{\prime}-D D D$ và $p$, p'-DDE là bảy năm (Binelli et al., 2003).

Cá và các yếu tố môi trường liên quan đến lưới thức ăn của chúng được phơi nhiễm cùng một mức độ với OCPs HCHs (Willett et al., 1998). Theo Buah-Kwofie et al (2018), mặc dù nồng độ $\alpha$ - và $\gamma$-HCH cao hơn đáng kể ở cá trê $C$. gariepinus so với cá rô phi $O$. mossambicus $(295,8 \pm 48,2 \mathrm{ng} / \mathrm{g}$ và $270 \pm$ $94,1 \mathrm{ng} / \mathrm{g}$, tương ứng) song không phải lúc nào cũng phát hiện được $\mathrm{HCHs}$ trong trầm tích với hàm lượng lớn do chúng có xu hướng phân bố sinh học dễ dàng hơn các OCPs khác trong các hệ thống sinh thái thủy sinh. Tương tự, heptachlor và các dẫn xuất của nó nhanh chóng được chuyển hóa thành dạng epoxit trong các hệ thống thủy sinh và dễ dàng lưu trữ trong các mô sinh học béo (WHO, 2004; 2012) nhưng hàm lượng phân tích thường không lớn, tuy nhiên nó vẫn phổ biến trong các mẫu mô thịt của nhiều loại cá cho thấy tính chất khả dụng sinh học của hợp chất này (Sikka et al, 1976). 
Nồng độ endosunfan và các hợp chất drins của nghiên cứu này cũng có xu hướng kết quả tương tự với các công trên, dù giá trị có thấp hơn. Kết quả nghiên cứu của BuahKwofie cho thấy hàm lượng endosunfan ở hai loài cá là như nhau $(394 \pm 133 \mathrm{ng} / \mathrm{g}$ và 395,5 $\pm 176 \mathrm{ng} / \mathrm{g}$, tương ứng). Sự tích lũy endosunfan cao hay thấp phụ thuộc vào dạng đồng phân được chuyển hóa trong mô cá và dạng $\beta$-endosulfan luôn có xu hướng phân hủy chậm hơn và kém bền vững hơn so với $\alpha$ - endosulfan (Breysse et al., 2015). Trong các chất drin thì aldrin là chất chiếm ưu thế ở mô thịt cá bớp B. sinensis $(74,496 \mathrm{ng} / \mathrm{g})$, tiếp theo là endrin $(68,119 \mathrm{ng} / \mathrm{g})$ và dieldrin $(61,645 \mathrm{ng} / \mathrm{g})$. Việc sử dụng các hợp chất drins đã bị câm ở Việt Nam cũng như nhiều nước trên thế giới, song sự hiển diện của chúng trong mô thịt cá chứng tỏ vẫn có sự phân hủy dẫn xuất aldrin và việc cấm sử dụng hóa chất bảo vệ thực vật thật sự chưa có hiệu quả.

Ở một mức độ nào đó, các khác biệt về hệ số tích tụ của các dẫn xuất OCPs trong mô cá có thể phản ánh sự khác biệt về ô nhiễm tại nơi chúng sinh trưởng. Cùng một loài nhưng sinh sống ở các môi trường khác nhau sẽ phơi nhiễm với các chất ô nhiễm khác nhau. Sự thay đổi nồng độ OCPs trong mô có thể là phản ánh sự khác biệt về gradient môi trường nuôi với trầm tích tại khu vực đó (Buah-Kwofie et al., 2018). Tập tính sinh trưởng và phát triển của các loài sinh vật thủy sinh liên quan chặt chẽ đến khả năng tích tụ sinh học của chúng (Barnhoorn et al., 2015). Tuy hàm lượng các chất OCPs phát hiện trong mô thịt cá bớp $B$. sinensis thấp hơn giới hạn cho phép song sự có mặt của các chất này chứng tỏ môi trường sinh sống của cá đã bị ô nhiễm hóa chất bảo vệ thực vật. Theo Buah-Kwofie et al. (2018), mức độ ô nhiễm cao hay thấp có thể liên quan đến một số yếu tố như độ tuổi, sự trao đồi chất và thói quen ăn uống của từng loài sinh vật. Trong tự nhiên, cá bớp $B$. sinensis thường sống trong các hang đất phân bố dọc theo bờ biển từ $\mathrm{Băc}$ đến Nam ở rừng ngập mặn, cửa sông và các vùng triều nên khả năng phơi nhiễm với các chất độc có trong môi trường trầm tích là rất lớn. Tuy nhiên, tại khu vực cửa sông Soài Rạp, cá được nuôi trong lồng, bè là chính vì vậy việc phát hiện các hợp chất OCPs trong mô thịt cá dù rất nhỏ cũng chứng tỏ môi trường nuôi cá đã bị ô nhiễm hóa chất này. Tiêu thụ thực phẩm là một trong những lộ trình phơi nhiễm chính của con người đối với chất gây ô nhiễm, nên việc xác định nguồn gây ô nhiễm từ thức ăn hay từ chính nguồn nước nuôi là một trong những nhiệm vụ quan trọng giúp ngành thủy sản có thể quy hoạch được các vùng cung cấp sản phẩm thực phẩm an toàn trong tương lai.

\section{KẾT LUẬN}

Kết quả khảo sát, phân tích và tính toán được hệ số tích tụ sinh học (BAF) và hệ số tích tụ sinh học trầm tích (BSAF) trong mô thịt cá bớp $B$. sinensis. cho thấy, trong tất cả mẫu mô thịt của cá hàm lượng DDTs là lớn nhất $(9,524 \mathrm{ng} / \mathrm{g})$, tiếp theo là aldrin $(1,209$ $\mathrm{ng} / \mathrm{g})$; $\mathrm{HCHs}(1,972 \mathrm{ng} / \mathrm{g})$; dieldrin $(1,743$ $\mathrm{ng} / \mathrm{g})$ và endosunfans $(1,053 \mathrm{ng} / \mathrm{g})$, nhóm thấp nhất là heptachlor $(0,807 \mathrm{ng} / \mathrm{g})$ và eldrin $(0,715 \mathrm{ng} / \mathrm{g})$. Đã phát hiện hàm lượng các hợp chất OCPs trong tất cả các mẫu trầm tích tại khu vực nghiên cứu. Giá trị trung bình của các hợp chất OCPs trong mẫu trầm tích thấp hơn giá trị giới hạn cho phép theo QCVN 43:2012/BTNMT và một số tiêu chuẩn khác trên thế giới. Hệ số tích tụ sinh học của các hoạt chất OCPs trong mô thịt cá bớp ở mức tích tụ rất thấp $(\mathrm{BAF}<100)$ riêng DDTs ở mức tích tụ thấp $(100<\mathrm{BAF}<500)$. Hệ số tích lũy sinh học (BSAF) của 7 loại hoạt chất trong trầm tích theo thứ tự Dieldrin $>$ DDTs $>$ Aldrin $>\mathrm{HCHs}>$ Endosunfans $>$ Heptachlor $>$ Endrin.

Loại bỏ ô nhiễm hóa chất bảo vệ thực vật của các sản phẩm thủy sản, trong quy hoạch vùng nuôi trồng thủy hải sản an toàn, mới có thể nâng cao chất lượng thủy sản ở Việt Nam.

\section{TÀI LIỆU THAM KHẢO}

Aamir M., Khan S., Tang M., Qamar Z., Khan A., Nawab J., 2016. Congener-specific evaluation of biota-sediment accumulation factor model for $\mathrm{HCHs}$ and DDTs under small-scale in situ riverine condition. $J$ 
Soils Sediments, https://doi.org. 10.1007/s11368-016-1579-y.

Arnot J. A., Gobas F. A., 2006. A review of bioconcentration factor (BCF) and bioaccumulation factor (BAF) assessments for organic chemicals in aquatic organisms. Environmental Reviews, 14(4): 257-297.

Australian Pesticides and Vertinary Medicines Authority (APVMA), 2012. Maximum residue limits in food and animal feedstuff. Agricultural and veterinary chemicals, APVMA 12.

Banerjee B. D, Koner B. C, Ray A., 1996. Immunotoxicity of pesticides: perspectives and trends. Indian Journal of Experimental Biology, 34: 72-78.

Báo cáo tình hình xuất khẩu thủy sản của VASEP, 2016.

Barnhoorn I. E. J., Van Dyk J. C., Genthe B., Harding W. R., Wagenaar G. M., Bornman M. S., 2015. Organochlorine pesticide levels in Clarias gariepinus from polluted freshwater impoundments in South Africa and associated human health risks. Chemosphere, 120: 391-397.

Binelli A., Provini A., 2003. POPs in edible clams from different Italian and European markets and possible human health risk. Mar Pollut Bull., 46: 879-886.

Breysse P. N., Taylor J., Pohl H. R., Mumtaz M., Ruiz P., 2015. Toxicological profile for endosulfan. Agency for Toxic Substances and Disease Registry https:// www.atsdr.cdc.gov/toxprofiles/tp41.pdf, (accessed 29 May, 2017).

Buah-Kwofie A., Humphries M. S., Pillay L., 2018. Bioaccumulation and risk assessment of organochlorine pesticides in fish from a global biodiversity hotspot: iSimangaliso Wetland Park, South Africa. Science of the Total Environment, 621: 273-281.

Chen W., Jing M., Bu J., Ellis Burnet J., Qi S., Song Q., Ke Y., Miao J., Liu M., Yang C., 2010. Organochlorine pesticides in the surface water and sediments from the
Peacock River Drainage Basin in Xinjiang, China: a study of an arid zone in Central Asia. Environ. Monit. Assess., 177: 1-21

Cheng W. W., Zhang A., Liu W., 2013. Risks from sediments contaminated with organochlorine pesticides in Hangzhou, China. Chemosphere, 90: 2341-2346.

Dai G. H., Liu X. H., Liang G., Xu M. Z., Han X., Shi L., 2011. Health Risk Assessment of Organochlorine Contaminants in Fish from a Major Lake (Baiyangdian Lake) in North China. Bull Environ Contam Toxicol., 87: 58-64.

Daniela M. L. d. S, Plínio B. d. C. L. A. M, Fernando M. L. J. S. S. P, Wagner E. P., 2008. Organochlorine pesticides in piracicaba river basin (São Paulo/Brazil): a survey of sediment, bivalve and fish. Quim Nova, 31(2): 214-219.

David M. W., 2010. Bioconcentration, Bioaccumulation, and Metabolism of Pesticides in Aquatic Organisms. In Reviews of Environmental Contamination and Toxicology, New York: Springer, pp. $1-132$.

Donaldson D., Kiely T., Grude A., 2002. Pesticide's industry sales and usage 19981999 market estimates. US Environmental Protection Agency, Washington (DC). Available from: http: //www.epa.gov/oppbead/ pesticides/99 pestsales/market-estimates.pdf.

Dương T. N., Tran Đ. T., Tran V. Q., 2013. Phân bố và tích tụ chất ô nhiễm hữu cơ bền $\mathrm{OCPs}$ và $\mathrm{PCB}$ trong vùng biển ven bờ phía Bắc Việt Nam. Tạp chí Khoa hoc và Công nghệ Biển, 13(1): 66-73.

Kaushik C. P., Sharma N., Kumar S., Kaushik A., 2012. Organochlorine pesticide residues in human blood samples collected from haryana, India and the changing pattern. Bull. Environ Contam Toxicol., 89: 587-591.

MacDonald, 1994 and U.S. Environmental Protection Agency, 1997a.

Nguyen H. M., Tu B. M., Hisato I., Natsuko K., Tatsuya K., Shin T., Pham H. V., Bui 
C. T., Shinsuke T., 2007. Persistent Organic Pollutants in Sediments from Sai Gon-Dong Nai River Basin, Vietnam: Levels and Temporal Trends. Archives of Environmental Contamination and Toxicology, 52(4): 458-465.

Nguyen Q. T., Đo T. T. H., 2012. Ảnh hưởng của thuốc trừ sâu hoạt chất Quinalphos đến hoạt tính men Cholinesterase và Glutathione-s-transferase của cá chép Cyprinus carpio. Tạp chí Khoa họ, 22a: 131-142.

Nguyen V. C., Nguyen T. P., 2011. Tổng kết một số nghiên cứu ảnh hưởng thuốc bảo vệ thực vật hoạt chất Diazinon lên cá lóc đồng Channa striata. Tap chí khoa hoc trường đại học Cần Tho, 17a: 133-140.

Pham K. Đ., Bui T. B., Vu Đ. L., 2015. Sự tích lũy một số kim loại trong cá chép (Cyprinus carpio) nuôi tại trại nuôi trồng thủy sản, Học viện nông nghiệp Việt Nam. Tạp chí Khoa học và Phát triể, 13(3): 394-405

QCVN 43:2012/BTNMT: quy chuẩn kỹ thuật quốc gia về chất lượng trầm tích.

Quyết định Về việc công bố Danh mục các loài thủy sinh quý hiểm có nguy cơ tuyệt chủng ở Việt Nam cần được bảo vệ, phục hồi và phát triển. Sách đỏ Việt Nam, IUCN, 2007.

Sankar T. V., Zynudheen A. A., Anandan R., Viswanathan P. G. N., 2006. Distribution of organochlorine pesticides and heavy metal residues in fish and shellfish from Calicut region, Kerala, India. Chemosphere, 65: 583-590.

Sikka H. C., Butler G. L., Rice C. P., 1976. Effects, Uptake, and Metabolism of Methoxychlor, Mirex, and 2,4-D in Seaweeds (No. EPA-600/3-76-048). Environmental Protection Agency, Office of Research and Development, Environmental Research Laboratory, USA, U.S. 9.

Singh, D., Chhonkar, P. K., Dwivedi B. S., 2014. Manual on soil plant and water analysis. Publisher: Westville Publishing House.
Sở Tài nguyên và Môi trường Thành phố Hồ Chí Minh, Báo cáo tổng hợp kết quả quan trắc chất lượng môi trường nước mặt sông Cần Giuộc năm 2017, DONRE, 2017.

Stefanelli P., Muccio A. D., Ferrara F., Barbini D. A., Generali T., Pelosi P., Amendola G., Vanni F., Muccio S. D., Ausili A., 2004. Estimation of intake of organochlorine pesticides and chlorobiphenyls through edible fishes from the Italian Adriatic Sea during 1997. Food Cont., 15: 27-38.

TCVN 5276-90: Thủy sản - lấy mẫu và chuẩn bị mẫu.

TCVN 5992:1995: Chất lượng nước - lấy mẫu - hướng dẫn kỹ thuật lấy mẫu.

TCVN 6648: 2000 (ISO 11465: 1993), Chất lượng đất - xác định chất khô và hàm lượng nước theo khối lượng - phương pháp khối lượng.

Tran M. P., Đo T. T. H., 2013. Ảnh hưởng của Dipterex đến đời sống thủy sinh vật và con người. https://tepbac.com/tintuc/full/Anh-huong-cua-Dipterex-den-doisong-thuy-sinh-vat-va-con-nguoi4836.html.

Tran T. A., Nguyan T. K. H., Nguyen Q. T., Đo T. T. H., Nguyen T. P., 2012. Ảnh hưởng của Quinalphos lên men Cholinesterase và tăng trưởng của cá mè Vinh Barbodes gonionotus. Tap chí Khoa hoc, 22a: 269-279.

Tran T. V. T., 2007. Đánh giá sự tồn dư và tích lũy của các hợp chất ô nhiễm cơ clo khó phân hủy tại các vùng cửa sông và đầm phá Thừa Thiên Huế, miền Trung, Việt Nam. Đề tài nghiên cứu khoa học của Trung tâm Hỗ trợ Nghiên cứu Châu Á, Đại học Huế.

Tsygankov V. Y., Boyarova M. D., 2015. Sample Preparation Method for the Determination of Organochlorine Pesticides in Aquatic Organisms by Gas Chromatography. Achievements in the Life Sciences, 9(1): 65-68.

U.S. Environmental Protection Agency, $1997 \mathrm{a}$ 
Wang B., Yu G., Huang J., Wang T., Hu H. Y., 2010. Probabilistic ecological risk assessment of OCPs, PCBs, and DLCs in the Haihe River, China. Sci World J., 10: 1307-1317

Wang N., Li Y., Shi L., Kong D., Cai D., Wang D., Shan Z., 2012. Pollution level and human health risk assessment of some pesticides and polychlorinated biphenyls in Nantong of Southeast China. Journal of Environmental Sciences, 24(10): 1854-1860.

Wepener V., Smit N., Covaci A., Dyke S., Bervoets L., 2012. Seasonal bioaccumulation of Organohalogens in Tigerfish, Hydrocynus Vittatus Castelnau, from Lake Pongolapoort, South Africa. Bull. Environ. Contam. Toxicol., 88: 277-282.

Willett K. L., Ulrich E. M., Hites R. A., 1998. Differential toxicity and environmental fates of hexachlorocyclohexane isomers. Environ. Sci. Technol., 32: 2197-2207.
World Health Organisation, 2004. Heptachlor and Heptachlor Epoxide: Background Document for Development of WHO Guidelines for Drinking-water Quality (Technical Document No. WHO/SDE/WSH/03.04/118) Geneva Switzerland.

World Health Organisation, 2012. Inventory of Evaluations Performed by the Joint Meeting on Pesticide Residues (JMPR). http://apps. who.int/pesticide-residues-jmprdatabase, Accessed date: 31 May 2017.

Wu C., Zhang A., Liu W., 2013. Risks from sediments contaminated with organochlorine pesticides in Hangzhou, China. Chemosphere, 90: 2341-2346

Yohannes Y. B., Ikenaka Y., Saengtienchai A., Watanabe K. P., Nakayama S. M. M., Ishizuka M., 2014. Concentrations and human health risk assessment of organochlorine pesticides in edible fish species from a Rift Valley lake - Lake Ziway, Ethiopia. Ecotoxicology and Environmental Safety, 106: 95-101. 